To reduce wasted knowledge and to learn how to commercialize innovation, let's start with what we know. Innovation needs money. Lack of investment capital reflects a risk reward calculation. Change the risk profile until the investment market responds.

- Colin Goodfellow, CEO, Kemptville District Hospital

\section{Train Building in Ontario: The Future of Local Health Integration Networks}

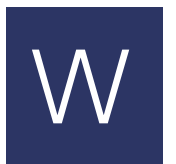

hile it may seem vastly premature to talk about the future of Local Health Integration Networks (LHINs) in Ontario before they have been formally established and before their governing legislation has been introduced, enough is known from the experience of other provinces to firmly place LHINs in a national and provincial context.

A common analogy is to compare regionalization to a train. In the classic tradition, you first decide where you want to go and the best way to get there, given available resources and technology. Second, you design the train to fit with the job that lies ahead. Third, you build the train along with the tracks and then get it moving. The other provinces have all built trains and are moving them down the tracks, although in many cases the train (or maybe the number of cars) has been changed along the way.

In the national context, LHINs appear to be a very modest beginning down the regionalization road.

LHINs are less of a move toward regionalization than any other province has taken. It is also taking place about 10 years later than elsewhere in Canada. Ontario has chosen not to follow the traditional regionalization train-building exercise of the other provinces. Ontario is slow to change and powerful vested interests are well-entrenched. As such, the type of regionalization train Ontario has built fits with the political sensitivities and realities of the province.

So with a modest beginning, it is inevitable that there will be considerable skepticism about how much it will be able to accomplish and how long LHINs will last in their current form.

In Ontario, it would appear as if the province has jumped to step three without clearly articulating the first two.

Unlike several other provinces Ontario did not engage in a royal commission to define a future vision and analysis of the healthcare system as a whole. Such undertakings in other provinces have served a useful role in defining for the health system, as well as the general public, the 'big' challenges and strategies to address them. LHINs have been established with only a general notion of how their role will 'fit' into the existing system and no clear statement about what the future of the health system in Ontario will look like.

So now that the LHIN train has been built (sort of) what might its future look like?

There is some room for optimism, with some obvious caveats.

First, Ontario has built a regionalization train and should be congratulated for having done so. While it's different than any build before in the country (except for the brief flirtation Quebec had with this model), it is important to acknowledge that the provincial government has recognized that the healthcare system cannot continue to be 'governed' entirely from a provincial centre.

Second, one hopes that the use of the term integration in the LHIN title is more than a word in the name. The integration agenda, especially when one delves below the surface, is exceedingly challenging and complex but is the most significant.

Third, assuming that LHINs get the tools to redirect funds and to define deliverables on a systems level, they will have the opportunity to be more than the merger of the regional offices of the Ministry of Health and Long-Term Care and District Health Councils. If they do not, then they will fall far short of what it expected. The significance of this cannot be understated. For example, if LHINs are able to set expectations and fund what is required to deliver an integrated diabetes strategy, then the organization of diabetes care in a region would look significantly different than it does today. This kind of an incentive and reward system would serve to break down organizational and service boundaries and move organizations, programs and services closer together. If LHINs cannot focus and engage in this kind of innovative and 'breakthrough' activity as their primary raison d'être, then what's the gain?

So what is expected of LHINs?

First of all, LHINs are expected to bring leadership and direction on a systems level and to exercise their role in a collaborative style.

Second, they are expected to bring regional leadership and adapt provincial priorities and strategic directions to the local environment.

Third, they are expected to articulate a future state for the health system within the region, in alignment with guiding principles and standards set at the provincial level.

Fourth, they are expected to be able to take this future state and craft strategies and priorities for genuine "system-building," much of which has been stated many times but never given an organizational framework within which to be realized.

On the dark side, LHINs run the risk of not being able to 
develop or fully articulate a strategic vision and direction. The expectations of LHINs are very high and the need for early returns, especially at the provincial level is significant.

The primary means of LHINs to affect change will come in two forms: (1) the ability to decide on the distribution of funds and (2) the ability to direct funds in strategically important ways that promote and reward health systems integration.

If their voice is silenced or muted on either of these fronts, the message will be that the "real" power base has not moved but continues to be housed at the MOHLTC and to a broader extent in downtown Toronto.

At the same time, without some serious investment in system-building, Ontario will reach the end of its health spending rope with little to show than more insatiable demands.

The LHINs will not be a panacea for the ills of the system. The system is simply too large and complex and the LHINs too small for that to be a realistic expectation.

What we should be able to expect of the LHINs is that they are able to meaningfully engage the public, health system organizations and health service providers in a collective sense of urgency that the integration agenda is important, meaningful and worthwhile.

The LHINs also need to demonstrate that they have the means and ability to translate ideas into action.

Symbols are important. They send messages that translate into perceptions and reputations. Messages such as "these people know what they are doing," "these people have the skills to do what needs to be done," "these people are showing real leadership" are important. If the LHIN can begin by being able to work in a way that delivers and sustains these messages, then some of the initial skeptics will be silenced. If they are able to mobilize the health system and facilitate delivery on a few key systems issues, even more skeptics will be silenced. If they are able to move the system into the domain where comparisons with regionalization in other provinces can be made in positive terms, then LHINs will have arrived.

In spite of what the LHINs need to do, the Ministry that created them and to whom they will report will in large measure determine their future. The full mandate of the LHINs needs to be realized and reinforced, especially by the province, if it is to be successful. If Ontario decides in the future that LHINs are limited, let it be because LHINs need to grow beyond what was originally envisioned, not because there is a call to return to the Balkanization of the present. If that happens, far more than the LHINs will be the losers.

- Steve Elson, Director, Integrated Strategic Alliances \& Networks, London Health Sciences Centre and St. Joseph's Health Care, London
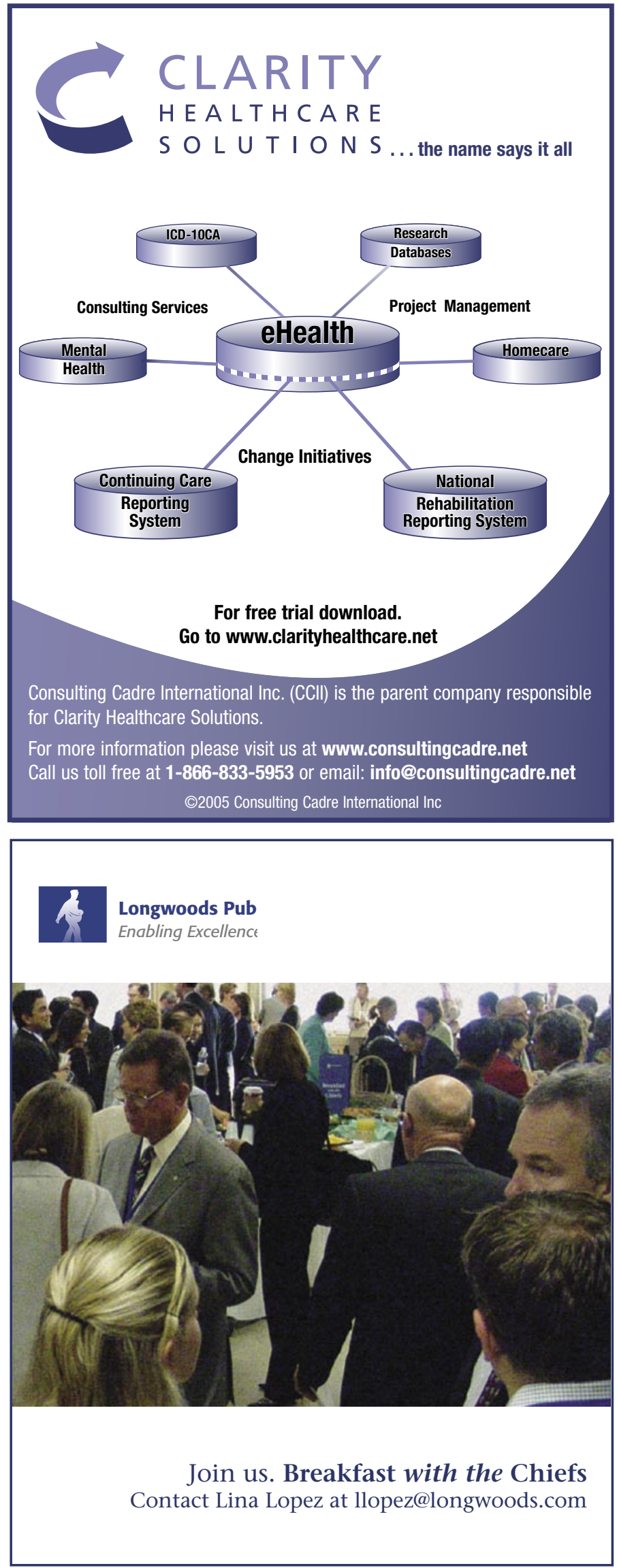